\title{
NUEVOS APUNTES A PROPÓSITO DE \\ LA SEGUNDA PARTE DE LA TORRE DE DAVID \\ MORALIZADA POR VÍA DE DIÁLOGOS \\ (¿DE JERÓNIMO DE LEMOS?) \\ Y DE UNA HISTORIA ACAECIDA EN UNA CIUDAD \\ DE ESTE REINO MUY PROVECHOSA ASÍ PARA RELIGIOSOS COMO PARA CASADOS ${ }^{1}$
}

\author{
JAVIER ESPEJo SuRós \\ Université Catholique de L'Ouest / Dialogyca \\ jespejo@uco.fr
}

$\mathrm{P}$ ara dar orden y concierto a estas líneas es necesario traer antes noticia de otras, dadas recientemente a las prensas, en las que ofrecía unas primeras notas acerca de un manuscrito custodiado en la Biblioteca Nacional de Viena (Österreichische Nationalbibliothek, Codex Vindobonensis Palatinus 11657. Sign. Cod. 11657 Han.) que incluye la Segunda parte de La Torre de David moralizada de Jerónimo de Lemos, extraviada durante varios siglos, así como una enteramente desconocida Historia acaecida en una ciudad de este reino muy provechosa así para religiosos como para casados (Espejo Surós 2017)². Conviene recordar, así, que cuanto conocíamos acerca de dicha Segunda parte era que el propio Jerónimo de Lemos la anunciaba ya en el prólogo de la primera:

Es de notar que el séptimo diálogo se me mostró tan copioso de materias provechosas a todo género de gente, que fui constreñido a dejarle en esta parte por acabar, para que de lo que de allí adelante procediere, se haga otro tratado tan grande y

\footnotetext{
1 Trabajo realizado en el marco del Proyecto de investigación: «Dialogyca: Transmisión textual y hermenéutica del diálogo hispánico» (FFI2015-63703-P) (MINECO/AEI/FEDER-UE), bajo la dirección de Ana Vian Herrero y Mercedes Fernández Valladares.

2 Más abajo el manuscrito vienés.
}

Edad de Oro, XXXVII (2018), pp. 75-95, ISSN: 0212-0429 - ISSNe: 2605-3314

DOI http://dx.doi.org/10.15366/edadoro2018.37.003 
mayor que este. Y por esto le uve de dividir: porque mi intento es hacer dos volúmenes, o libros tan pequeños, que se puedan traer en el seno como buxeta de medicina preservativa para todas enfermedades, como parece en las muchas diferencias de materias que se tocan en estos siete Diálogos con el octavo que al fin se habrá de añadir. Porque aprovechándonos de los siete que significan todo lo que se pasa en esta vida, podamos gozar del octavo, por el cual se entiende el descanso de la gloria ${ }^{3}$.

Más adelante, en la Tabla de diálogos que figura a modo de índice de la primera parte y, más precisamente, en el sumario del séptimo diálogo, leemos: «Este postrero diálogo queda imperfecto, por lo que lo restante del, con otros diálogos que se le añaden, hacen otro cuerpo tanto y mayor que este». En las líneas finales del séptimo y último diálogo de los que componen la primera parte, los personajes se emplazan expresamente a retomar en breve la conversación; una conversación que dará lugar, necesariamente, a la continuación del tratado. Discurren así los personajes:

Paréceme que aunque no quede del todo concluido ni averiguado por hoy, que nos volvamos mañana, con un presupuesto que he pensado después que estamos aquí, y querría que estudiásemos sobre ello, y es. Que hagamos cuenta, que cualquiera de estos estados es bueno y perfecto, y que es digno de ser elegido, cada uno en su manera, y que no haya dificultad ni falta en ninguno de ellos. Pongamos caso que yo quiero ser fraile, y que me cuadra más este estado que otro alguno. Veamos, ya que yo estuviese aficionado, y con esta determinación, qué orden será bien escoger: pues por la gloria de Dios hay tantas y tan diversas en hábitos y en costumbres, como vemos que hay en el mundo. Lo mismo hemos de hacer cuenta, que vos queréis ser clérigo, y que este estado queréis seguir: tratemos qué manera, qué ejercicio o cómo os emplearéis en él. Porque ya veis que hay clérigos, ocupados en diversos oficios: unos tienen cargo de ánimas; otros se contentan con solas sus pitanzas; otros sirven a los obispos que de provisores, que de visitadores, que de capellanes; otros entran en las iglesias catedrales, que para el pulpito, que para leer, que para abogar y defender sus pleitos; y otros que son beneficiados en las dichas iglesias; bien habrá aquí que averiguar cuál será lo mejor. Ítem pongamos caso que un grande amigo nuestro se quiere casar, y nos ruega que le aconsejemos qué manera de vivienda seguirá en el mundo, donde hay tantas diversidades de oficios

3 En las citas, tanto para la primera como para la segunda parte de La Torre de David así como para la Historia acecida, transcribo el texto modernizando la ortografía y la puntuación. Sigo el uso moderno para la acentuación, mayúsculas o la división de palabras; resuelvo confusión de $b-v, \mathrm{~h}$ diacrítica, alternancias $(i / j ; u / v))$. Desarrollo abreviaturas y contracciones. Conservo las formas verbales esdrújulas en -ades, -edes («supiésedes», «llamábades»). Para la primera parte, manejo la primera edición conocida, La Torre de Dauid: moralizada por via de dialogos para todo genero de gentes compuesto por Hieronymo de Lemos, de la orden de S. Hieronymo. En Salamanca en casa de Andrea de Portonarijs, 1566 (pero 1567), ejemplar en la BNE, con sign. R/7166 (Ruiz Fidalgo 1994: n. ${ }^{\circ}$ 646). Para la segunda parte y la Historia acaecida, uso el ejemplar único vienés reproducido a petición del equipo Dialogyca. 
y ejercicios con que los hombres que militan debajo de la bandera del matrimonio usan el día de hoy. Sobre estas tres cosas será nuestra plática y conferencia. Así vendremos a concluir y cumplir con nuestro principal intento [...] (ff. 388v-390r).

Fray Baltasar de Toledo, Vicario del monasterio del Parral de Segovia, encargado de poner orden y publicar los materiales dejados inconclusos por Lemos, fallecido unos años antes sin ver impreso el fruto de sus esfuerzos, afirmaba al publicar la primera parte que había buscado sin éxito la segunda, razón por la cual pedía encarecidamente a quien la tuviere que la sacara a la luz pública:

Todo el tiempo que la tuve en mi poder hasta el fin y sepultura de su autor [se refiere a la primera parte], estuve en el escrúpulo, que después me han puesto los letrados a quien he mostrado, que han sido hartos. Los cuales todos a una voz me decían, que era gran cargo de consciencia encubrirla, y no poner sobre el candelero una candela tan resplandeciente como esta [...] Por tanto suplico a Vuestra Ilustrísima, reciba este librico, y le ampare, y dé tanto favor, que obligue y constriña al que tiene la segunda parte de esta obra, que la manifieste y saque a luz ${ }^{4}$.

La noticia de la pérdida o hurto de la Segunda parte de La Torre de David la recogía Diego de Colmenares en su Vida y escritos de escritores segovianos (1640):

Escribió Gerónimo de Lemus [sic] en latín un libro que intituló Turris David, dividido en siete diálogos devotos, y muy doctos; si los gozáramos, como sabemos que él los escribió. Murió antes de imprimirle año mil quinientos sesenta y tres. Tradújole en romance un religioso de su Orden, aunque no de sus letras y caudal, y echó algunos remiendos sobre sano, y de paño muy diferente, deslustrando con muchas desigualdades la alteza del título y asunto. Dedicóle a nuestro Obispo don Gaspar de Zúñiga, ya Arzobispo de Santiago, y aunque dislustrado alcanzó estimación, y deseos de que apareciera la segunda parte, hurtada, o perdida, que así desmendran los escritos en ausencia de su autor (Colmenares 1640: 732-733).

4 Carta de fray Baltasar de Toledo a Gaspar de Zúñiga y Avellaneda, arzobispo de Santiago, que integra los preliminares de La Torre de David, moralizada por vía de diálogos, para todo género de gentes. El compendio de diálogos de nuestro jerónimo gozó de cierta fortuna editorial pues, además de la citada de 1567, conocemos otras ediciones de Salamanca, en casa de Matías Mares, 1571 (Ruiz Fidalgo 1994: 794); Salamanca, en casa de Juan Bautista de Terranova a costa de Miguel de Aviñón, 1573 (Ruiz Fidalgo 1994: 847a); Salamanca, en casa de Juan Baptista de Terranova: a costa de Diego de Ureña, 1573 (Ruiz Fidalgo 1994: 847b); Salamanca, en casa de Pedro Lasso, 1578 (Ruiz Fidalgo 1994: 973); y, finalmente, Medina del Campo, en casa de Francisco del Canto: a costa de Iuan Boyer, 1584 (Pérez Pastor 1887: 202).

5 Jerónimo de Lemos recibió el hábito de san Jerónimo en el convento de Nuestra Señora del Parral, donde profesó en 1537, según Colmenares (1640: 732-733) y Baeza y González (1877: 92-93). Rafael Hernández, en la relación de los frailes que tomaron el hábito en el monasterio de Santa María del Parral, afirma que fray Jerónimo hizo profesión «lunes segundo día del mes 
Colmenares, como se advierte, además de aludir a la continuación perdida, daba por hecho que la primera parte de La Torre de David fue compuesta en latín y traducida después con escasa pericia por un hermano de la Orden ${ }^{6}$. Lo cierto, sin embargo, es que no parece que existiera tal original latino. El mismo Lemos, de hecho, se ufanaba en el prólogo de la primera parte de haber compuesto su obra «en lengua vulgar y común para todos» ${ }^{7}$. Para saber un tanto más acerca de dónde acaba la mano de Jerónimo de Lemos y empieza la de fray Baltasar de Toledo, en lo que a la primera parte se refiere, puede acudirse a la Licencia real dada en la villa de Madrid a quince días del mes de noviembre de mil quinientos treinta y cuatro, en donde Juan Hernández de Herrera, secretario de Cámara de Su Majestad, afirma lo siguiente:

Por cuanto por parte de vos, Fray Baltasar de Toledo, Vicario del monasterio de nuestra señora del Parral de la orden de San Jerónimo, nos ha sido hecha relación

de abril y segundo día de Pascua de Resurrección año de mil y quinientos treinta y siete». Hernández Ruiz de Villa (1958: 157). Citado por Marino (2013: 319). Sobre Lemos véase, además, Vergara y Martín (1904), Sáinz Rodríguez (1984: 210-227) y Rodríguez (1932-1995: vol. 9, col. 588).

6 Nicolás Antonio asegura que Lemos había redactado inicialmente sus diálogos en latín y que, al verse sorprendido por la muerte, los dejó en cuartillas (schedis), retomadas por un compañero de la Orden: «F. Hieronymus de Lemos, segoviensis, Hieronymianus ad coenobium Parralis monachus, libellum edidit, doctum sane \& pium, septem dialogis comprehensum, quem Turrim [sic] David Latino, quo erat scriptus, idiomate vocavit. Hunc morte praeventus in schedis reliquit anno MDLXIII. Cui tamen pro Latino, hoc est germano ipsius auctoris, successit alius Hispanicus, a sodali Hieronymiano quodam male confutus, hoc titulo: Torre de David. Salmanticae apud Adream de Portonariis 1567. \& apud Petrum Lasso 1578 Editum vidimus Italica etiam lingua sic inscriptum: Armeria religiosa, Dialogo spirituale per amare i Servi di Dio, interprete Fr. Julio Zanchini de Castiglionchio, una cum Joannis de Bonilla tractatu de Pace animae. Florentiae apud Georgium Marescotti 1579» (Antonio 1783, 587-588). La traducción italiana referida por Antonio lo es únicamente del cuarto diálogo, manejando la edición de Medina del Campo en 1584, referida más adelante, según Marino (2013: 340-359).

7 Fray José de Sigüenza, en la Segunda parte de la Historia de la Orden de San Gerónimo, publicada en 1600, se extiende también en la cuestión de la torpe mano de quien hubo de asumir la tarea de dar a conocer la Primera parte: «Pudiera yo añadir a esta memoria de los antiguos, y primeros algunos de los que yo vi [se refiere a un elenco de ilustres monjes jerónimos de los que va dando noticia], y no los tengo olvidados, ni puedo, porque no son de menos santidad que los pasados. Como es del siervo de Dios fray Gerónimo de Lemos, varón docto, y santo. El que escribió un libro que anda por ahí, que se llama La Torre de David. Bien creo yo si le topara que no le conociera por suyo, porque dexado a parte que él le escriuio en Latin, y sin algunas frialdades y niñerias que en el se veen, en la substancia y nobleza del sujeto tiene poco de torre, y de Dauid nada. Sacole a luz vn religioso que auia estudiado, y gastado poco azeyte» (Sigüenza 1907: 550). A propósito de una supuesta primera versión en latín, es concluyente la reflexión de Abad: «En la licencia del Rey [...] se dice que el libro es de Fray Jerónimo de Lemos y que se intitula Torre de David, sin mentar para nada original ninguno latino. Y lo que es más, el autor, en el prólogo escribe: "Porque tengo entendido, que redundará utilidad a la Patria por ser en lengua vulgar y común para todos". El lenguaje y estilo todo del libro está diciendo que el original se escribió en castellano. Sería un milagro de adaptación una traducción tan suelta y tan castiza [...]» (Abad 1954: 48). 
diciendo que vos avíades trabajado en escribir y sacar en limpio un libro que compuso fray Jerónimo de Lemos intitulado La Torre de David.

Del mismo modo, en la Licencia de Fray Jerónimo de Alabiano, Prior del monasterio de San Bartolomé de Lupiana, leemos:

[...] por vuestra carta [de Fray Baltasar de Toledo] me hicisteis saber que el venerable padre Fray Jerónimo de Lemos, profeso de dicho monasterio del Parral, compuso un libro que intituló Torre de David, en que introduce algunos diálogos. Cuya doctrina será útil a todo género de personas que con propia afección los leyere. E que prevenido de la muerte el dicho Fray Jerónimo de Lemos, no los pudo acabar y poner en perfección. E que vos, viniendo los dichos diálogos a vuestro poder, e viendo que si se imprimiesen podrían ser provechosos a la república Christiana, trabajaste en los recopilar y sacar en limpio ${ }^{8}$.

Puede afirmarse, así, que la función desempeñada por Baltasar de Toledo fue la de recopilar y sacar en limpio los siete diálogos que conforman La Torre de David moralizada por vía de diálogos para todo género de gentes, impresa por primera vez en 1567. En el volumen que contiene la segunda parte, fray Baltasar desaparece. Tanto en el lomo de la encuadernación, en donde se lee, arriba, Varii dialogi Hispanici [...] P. II Hieronimy De Lemos y, abajo, Codex M Theologicus NDCIII Olim $S$. N.; como en uno de los folios en blanco sin numerar que preceden al texto, en donde figura un expreso Pars II Operis inscripti 'Turris David. Autore: Fr. Hyeronymo de Lemos. O. S. Hieronymi', la atribución a Lemos es rotunda.

El Codex Vindobonensis Palatinus 11657 (sign. Cod. 11657 Han) de la Österreichische Nationalbibliothek consta de 438 folios manuscritos encuadernados en papel cartáceo («chartaceus»), en letra redonda, por lo general perfectamente legible y, con visos de veracidad, del siglo xvi. El manuscrito incluye, en efecto, en los ff. 1r-348v, la Segunda parte de La Torre de David moralizada, rescatada ahora del olvido cuatro siglos después, compuesta de cuatro diálogos y, a continuación, una Historia acaecida en una ciudad de este reino muy provechosa asi para religiosos como para casados (ff. 349r-438v), integrada, a su vez, por cuatro nuevos diálogos 9 . De todo ello nos puso sobre la pista una mención extensa en un

8 Cito por Jerónimo de Lemos, La Torre de Dauid: moralizada por via de dialogos para todo genero de gentes compuesto por Hieronymo de Lemos, de la orden de S. Hieronymo. En Salamanca en casa de Andrea de Portonarijs, 1566 (1567), BNE, R/7166. Cfr. Ruiz Fidalgo, n. ${ }^{\circ}$ 646. Consta de un prólogo de fray Jerónimo de Lemos y, en efecto, de hasta siete diálogos.

$9 \quad$ La noticia del catálogo electrónico recoge: Operis inscripti 'Turris David' Pars altera dialogos 4 morales hispánicos comprehendens. (Nr. 1) Lemos, Hieronymus de: Operis inscripti 'Turris David' Pars altera dialogos 4 morales hispanicos comprehendens. (span.). (Nr. 2) Lemos, Hieronymus de: Dialogi quattuor inter duos fratres et duas sorores de vita religiosa et coniugali. 
catálogo publicado entre finales del siglo XVIII y principios del XIX, el de Michael Denis, Codices Manuscripti Bibliothecae Palatinae Vindobonensis Latini Aliarumque Occidentis Linguarum, en cuya entrada número 600 de la segunda parte del primer volumen, se ofrecía una amplia y precisa descripción del manuscrito (Denis 1794: 600) ${ }^{10}$.

La rúbrica del primer diálogo de los cuatro que encontramos en la segunda parte confirma lo dicho por Lemos en la primera parte. Prudencio y Didino, los mismos interlocutores que se emplazaban a dialogar en el futuro, se encuentran de nuevo, dispuestos a reanudar la plática:

Comienza el primer diálogo entre los dos estudiantes, Prudencio y Didimo que es el que quedó comenzado en la primera parte de esta obra. Estos estudiantes habiendo mirado lo que habían de tratar cuenta cada uno lo que ha visto y hallado en la Torre de David, y así señala cada uno de ellos el estado a que más se aficiona, declarando en esta plática muchos pasos de la Sagrada Escritura.

En esas otras páginas a las que aludía al principio de estas traté de mostrar que, más allá del empleo del diálogo, existe un principio de identidad formal y funcional entre las distintas partes y composiciones que ahora conocemos y que, de un modo u otro, aparecen expresamente atribuidas a Jerónimo de Lemos. El uso de motivos e inquietudes comunes o la coincidencia de estilo así como ciertas estrategias ligadas al empleo del diálogo u otros recursos narrativos, como el acopio de citas tomadas de las sagradas escrituras, convenientemente anotadas, así como de dichos populares, refranes, cuentos tradicionales y voces castizas, permitían afirmar, con las debidas precauciones y a modo de hipótesis de trabajo, que las distintas piezas están cortadas del mismo patrón y que bien pudieran ser obra de un mismo autor. El conjunto de textos, por lo demás, ofrece un puñado de reflexiones corrientes en torno a un abanico reducido de estados y condiciones (seglar, casado, fraile, monja, estudiante), concluyendo que el estado monacal es el más perfecto, así como varias quaestiones triviales de vita religiosa et coniugali. La redacción de Las Torres de David y de la Historia acaecida coincide en el tiempo con la decimocuarta sesión del Concilio de Trento, de 11 de noviembre de 1563 , de la que surge la doctrina sobre el sacramento del matrimonio ${ }^{11}$. El ambiente y propósito de los trabajos tridentinos explica, a su vez, la especial relevancia que adquieren en los textos atribuidos a Lemos las continuas apelaciones a la necesaria ejemplaridad de la vida del religioso.

10 La noticia la retoma el volumen VII del Tabulae codicum manu scriptorum, praeter graecos et orientales in Bibliotheca Palatina Vindobonensi asservatorum (1875: 26).

11 A este propósito puede verse Brandenberger (1996), Caamaño (2007) y Pérez García (2016). 
Llegados a este punto retomo la reflexión, con objeto tanto de avanzar en el conocimiento de las obras descubiertas como de ensayar nuevas lecturas no siempre coincidentes con las que fueron mis primeras impresiones.

La Segunda parte de La Torre de David no cuenta con licencias, dedicatorias o prólogo. Arranca con el primero de los cuatro diálogos que lo componen (ff. 1r-51r, el f. 51v, en blanco).

El diálogo está dividido en diez secuencias numeradas, cada una de ellas, excepto la primera, introducidas por un epígrafe:

1. [sin epígrafe].

2. f. 5r: De algunas excelencias de la sagrada escritura.

3. f. 9v: De los tres estados aplicados a tres apóstoles [San Pedro, Santiago y San Juan ${ }^{12}$ ] y a tres virtudes [teologales: fe, esperanza y caridad].

4. f. 15v: De la virtud de la fe.

5. f. 21r: De la virtud de la esperanza.

6. f. 25r: De la virtud de la caridad.

7. f. $28 \mathrm{v}$ : De algunos bienes del matrimonio.

8. f. 34r: De las excelencias del estado eclesiástico.

9. f. 37v: Del estado monacal y de sus excelencias.

10. f. 40v: De la conclusión de todo este diálogo.

El propósito de los interlocutores (Prudencio, estudiante y Didimo, estudiante) es mostrar «que no hay más de tres estados en la Cristiandad, que son el de los casados, el de los clérigos y el de los religiosos que llamamos frailes y monjes» (f. 10r). El más perfecto es este último. Con la intención de demostrarlo, establecen una singular ecuación entre estados, apóstoles y virtudes teologales:

Veis aquí los tres santos apóstoles que escogió el hijo de Dios para sus secretos y maravillas y en ellos parecen cifrados y resumidos los tres estados que también escogió

12 «Y no permitió [Jesús] que nadie le acompañara, a no ser Pedro, Santiago y Juan, el hermano de Santiago» (Marcos 5, 37). «Prudencio: Digo pues que entendamos en estos tres apóstoles, los tres estados que hay en la Iglesia de Dios y que así como nuestro redentor escogió estos tres apóstoles para hacerles participantes de sus misterios y maravillas, así también escogió estos tres estados para que los cristianos como gente escogida entre todos los del mundo se pudiesen salvar en cualquiera de ellos que escogiesen. Por San Pedro, que fue casado, se entiende el estado de los casados. [...] San Pedro se señala más que todos en la virtud de la fe y dio mayores muestras de ella que los otros. [...] Por Santiago que quiere decir suplantador o el que engaña, entiendo yo aquí el estado clerical así en la vida y muerte como en la significación del nombre [...] un engañador de los vicios [...] El estado de los frailes en este lugar se entiende por San Juan, hermano de Santiago, [...] San Juan fue virgen y a esta causa más privado y más querido del hijo de Dios» (f. 13v). 
Dios para que los hombres se salven. Así mismo veis cuán al propio resplandecen en ellos las tres virtudes teologales sin las cuales ninguno se puede salvar (f. 14r).

El diálogo ampara, en el marco de una exposición acerca De la virtud de la fe, la acción de la Inquisición contra aquellos herejes afectos a la espinosa cuestión de la justificación por la fe:

[...] a esto tiene respondido nuestra madre la santa Iglesia y aun si bien me acuerdo, este santo concilio tridentino dice en la sesión 6 capítulo 8 que todas esas autoridades y las demás a ellas semejantes se han de entender en el sentido que la santa madre Iglesia las ha entendido y declarado (ff. 18v-19r).

El diálogo segundo (ff. 52r-166v) tiene por interlocutores a Abdano y Dobrino, hermanos (no encontramos al inicio, como sí ocurre en los otros diálogos, una indicación explícita de quiénes van a ser los interlocutores):

Comienza el segundo diálogo entre dos hermanos. El uno buen letrado y gran pecador llamado Abdano y el otro sin letras y gran siervo de Dios llamado Dobrino. $\mathrm{Y}$ el Dobrino se esfuerza a persuadir al hermano Abdano con buenas razones a la lección sagrada y a la conversación religiosa católica y honesta y devota. Y el Abdano se excusa con arrogancia de sus letras. Al fin el Dobrino con su humildad y caridad y perseverancia le persuade al ejercicio de la virtud. Trátanse muchas y saludables materias para el bien y quietud de la consciencia y para apartar de los vicios a los muy habituados a ellos.

Está dividido en catorce secuencias numeradas:

1. f. 52r: Disfrute que se saca de oír la Palabra de Dios.

2. f. 58r: De los daños y males que viene a los que no quieren oír la palabra de Dios.

3. f. 64r: Del fruto que se saca de la lección de buenos libros y el daño que hay en lo contrario.

4. f. 69r: Del peligro que siguen los sabios y poderosos si no viven bien.

5. f. 76r: De la utilidad del conocimiento de sí mismo y el daño de lo contrario.

6. f. $82 \mathrm{v}$ : Del peligro en que están los que viven mucho tiempo en pecado mortal.

7. f. 89r: Del provecho de la memoria de la muerte y del daño de su olvido.

8. f. 98r: Contra la hipocresía.

9. f. 106v: Cuánto nos importa deja el juicio a cuyo es.

10. f. 112v: De la misericordia de Dios y de cómo nos debemos aprovechar de ella. 
11. f. 121v: Cómo los pecadores están dormidos y enfermos.

12. f. 132v: Del provecho que trae consigo la buena confesión y del daño de la no tal.

13. f. 141v: Contra las excusas que dan los pecadores.

14. f. 152r: De las grandes muestras que Dios usa para llevar a los hombres a sí.

Sin duda, el más entretenido de los capítulos es el tercero, Del fruto que se saca de la lección de buenos libros y el daño que hay en lo contrario, en el que se arremete contra los libros de caballerías, por más que la crítica, ciertamente, sea convencional y encuentre apoyo en lugares comunes:

Dobrino: Tómalos [los libros] alguno por vía de pasatiempo y no solo pierden [/f. 64v] el tiempo mas corrompen las buenas costumbres, enseñan vicios, ciegan los buenos entendimientos y dañan grandemente la juventud y mocedad cristiana. Y cuánto se corre esta pestilencial mercadería pregúntenlo a los que alquilan estos libros con que se ha inficionado de esta nuestra Castilla. Porque verdaderamente que esta lección de libros de caballerías, de fábulas, de amores y de ficciones mentirosas es una ponzoña dulce y sabrosa píldora dorada y una invención disimulada y compuesta por el demonio y una granjería suya con que aparta a muchos del camino de la camino de la virtud incitándolos con sus halagüeñas palabras a seguir los vicios... Porque claro está que el cristiano que tiene doctrina sana y aprobada por la Iglesia y esta para diversos gustos y disonancias [/ f. 65r] [...] y se ocupa en leer un Amadís de Gaula, en un Esplandián, en un Primaleón, en un don Florisel de Niquea, en una Diana y otros semejantes libros que de tal podremos temer no le acaezca en la muerte. El castigo que se le aparejaba al glorioso nuestro padre San Jerónimo cuando por haber leído con afección las obras de Tulio y de otros gentiles por la composición y elocuencia del estilo siendo llevado ante el tribunal del verdadero juez fue gravemente castigado...

ABDano: Tanto quiero yo mis libros que vos menospreciáis que no los daría por hartos dineros pues me alivian de hartas pesadumbres que al hombre se le ofrecen cada hora y no son tan malos como vos los hacéis. No sin causa dijo Plinio que solía decir un gran filósofo que no había libro tan malo que no tuviese algo de bueno.

Dobrino: Yo os certifico que andan por ahí y tenéis vos hartos de ellos tan malos y abominables que al sentir y parecer de muchos doctos y santos varones los habían de quemar y mandar que jamás se imprimiesen porque estragan las ánimas tiernas de los que no se recatan avisadamente de ellos, pues qué estrago harán en los ignorantes y rudos lectores.

En el diálogo tercero (ff. 167r-264r, f. 264v en blanco), los interlocutores son Senesio, padre, y Adolino, hijo. De su contenido, tal y como ocurre en el resto, da buena cuenta el sumario: 
Comienza el tercer diálogo entre un padre muy viejo llamado Senesio y un hijo suyo llamado Adelino. Entrambos leídos y doctos en diversas facultades. Moralizanse algunos pasos de la sagrada escritura. $\mathrm{Y}$ al fin vienen a tratar de los males y bienes que hay en la vejez y en la mocedad.

En el diálogo cuarto (ff. 265r-348v), finalmente, aparecen de nuevo los mismos personajes que encontrábamos en el primero, a saber, Didino, ahora presentado como clérigo y Prudencio, ahora religioso:

Diálogo Cuarto. Entre un Fraile y un clérigo que alcanzándose en un camino vinieron a reconocer la grande amistad que en otro tiempo habían tenido y tratando el uno y el otro de sus estados y el contento que tienen, viene a declarar algunas dudas de la Torre de David y la diferencia que hay en la vida y estado del uno y del otro. Llamase el clérigo Didimo y el Fraile, fray Prudencio.

La Historia acaecida en una ciudad de este reino muy provechosa así para religiosos como para casados (ff. 349r-438v), por su parte, llama la atención, primero que nada, por su título, distinto de la producción precedente conocida de Lemos y más propio, a decir verdad, de otras tipologías discursivas. Viene precedida de un Prólogo y argumento (ff. 349r-349v):

En una ciudad de este reino estaba un hombre honrado casado con una noble señora y por ser ella un poco descuidada, y él no bien acondicionado, vivieron algunos años mal casados. El marido tenía un hermano fraile, y la mujer una hermana monja. El marido solía ir a comunicar sus disgustos con su hermano el fraile, y ella daba parte de sus trabajos a su hermana la monja. Por otra parte, el fraile estaba tan descontento con el estado de la religión que había tomado, que muchas veces estaba determinado de dejar el [f. 349v] hábito, y la monja se veía tan desconsolada, que muchas veces se deseaba la muerte viéndose cautiva para siempre. Fueron tantas las quejas, que los casados a sus hermanos dieron, y tantos los peligros que tenían y lazos en que a cada paso caían los de su estado, que no solamente los religiosos tuvieron por gloria el estado que habían elegido, mas con sus exhortaciones y buenos consejos reconciliaron a los casados de tal manera, que puniendo cada uno un poco de consideración de su parte volvieron a vivir en grande unión y conformidad y así aprobaron los unos y los otros el estado, a que Dios los había llamado, y reconocieron no estar la falta en el estado de vida, si no en el no saber usar de él como debían. Va repartida en cuatro diálogos, en el primero entra el casado y el fraile y después la casada y la monja.

La correspondencia es plena, de nuevo, entre lo anunciado y cuanto sigue. En el diálogo primero (ff. 350r-364v), los interlocutores son un fraile y un casado. Este último, desabrido con la carga del matrimonio va al monasterio a dar parte de sus desconsuelos y trabajos a su hermano el fraile. El cual le consuela 
prometiéndole buen suceso en su estado si aprovechase de algunos avisos que le dará, con lo cual el casado va un tanto satisfecho; y el religioso viendo el desconsuelo que su hermano tenía, vuelve sobre sí y aprueba y alaba el estado que tenía. Arranca con las quejas de ambos interlocutores; el uno, por las fatigas del matrimonio («Lo que más me fatiga es ver la poca paz que tengo en mi casa y así no entro en ella si no es a comer o a dormir y aun esto es por fuerza y a más no poder. Los trajes y gastos de mi mujer son sin medida, las demandas de cada hora no tienen término, daca [da acá] para esto daca para estotro», f. 352); el otro, el fraile, por lo aburrido de su existencia así como de que, cuando merece visita, solo es para contarle penas. Finalmente, acuerdan seguir senda segura, La Torre de David, que es, se nos dice, la sagrada escritura:

[...] he oído decir que en La Torre de David, que es la sagrada escritura, se hallan todas las armas que son menester para defenderse el hombre de todos los acaecimientos de este mundo así prósperos como adversos, déjeme dar vueltas por allá que espero en Dios que hallase lo que para esa su desgracia y desconsuelo es menester. Porque así como el refugio de todas las necesidades y fatigas de este mundo es la oración, así para tomar avisos, doctrina, esfuerzos, consuelo y consejo está esta torre muy (a)bastecida. Y así de aquí a que vuelva encomiende muy de veras a dios este negocio con continuas oraciones y yo también de mi parte haré el oficio de hermano, así en esto como en escoger de esta torre las armas que me parecerán serme / necesarias contra los enemigos que me dice ha (f. 362r).

El diálogo segundo es entre mujeres (ff. 365r-381r), casada — la una—, monja -la otra-:

En el cual se va continuando la historia, quejándose la casada a la monja de sus descontentos, desganas y desasosiegos. La cual aunque lo estaba mucho más con su encerramiento lo disimula y la consuela (f. $365 \mathrm{v}$ ) con palabras que después aplica para su misma consolación.

Los procedimientos son análogos: primero, ambas se quejan, la casada porque no soporta a su marido; la monja, bien porque el resto de mujeres, a pesar de sus cuitas de casada, «gozan más del mundo que nosotras, que estamos aquí emparedadas»; bien porque nadie viene a verlas («como si me dejaran ya muerta»); segundo, acuerdan encontrar soluciones en un libro sabio, que ya no es el Libro, sino «un librito que me trajeron el otro día que da muchas reglas de bien vivir no solo a los religiosos y religiosas, también a los casados y casadas, y entiendo que hallaré allí algunas cosillas con que podella [sic] aprovechar para pasar con igual corazón todas estas dificultades». El librito en cuestión ya no es la palabra sagrada sino la propia primera parte de La Torre de David de Lemos, referida veladamente: 
CASADA: Tengo necesidad yo dese librito. Digame por vida suya cómo se llama porque me le haga buscar.

Monja: No hay necesidad de eso porque se lo terné aquí para cuando venga y le terné señalado lo que me acuerdo en él haber leído que (como digo) le será muy provechoso.

En los diálogos tercero y cuarto, los portavoces del estado religioso (fraile y monja) van a entregarse a un acto de reconocimiento de culpa y propósito firme de enmienda. Sus quejas dan paso al consejo sabio fruto de la lectura de las Escrituras y, además, del libro de Lemos.

En el diálogo tercero (ff. 381v-414v) «de la mesma historia entre los dos hermanos que quedaron aplazados para volver a la plática comenzada. En el cual el fraile comunica al hermano seglar lo que ha estudiado en la Torre de David y toma para sí lo que le toca para vivir él más contento con el estado que tiene», los personajes, que se refieren a la primera parte de La Torre de David ya como obra impresa, comparten gustos literarios, entre los que destaca fray Luis de Granada. Conviene extenderse en la cita:

[f. 412v:] CASADO: hame tanto consolado con su plática aunque no llevase de aquí otra cosa sino haber entendido el provecho que se saca de la lección de la Torre de David bastara para enviarme muy contento pues con estoy avisado de cómo he de regir y gobernar mi casa y sobre todo cómo he de mejorar mi vida y costumbres que es doblarme la obligación de no descuidarme en lo que tanto me va. Dele nuestro señor el galardón que yo no soy tan poderoso de saberle agradecer tan buena obra, mas en fin aquel por cuyo amor lo ha hecho se lo pagará. Haga cuenta que ha rescatado mi ánima y remediado toda mi familia y casa y dado buen fin a mí y a mi mujer e hijos que según los pasos que llevábamos todo iba perdido. Por lo que, de aquí adelante, verá y sabrá de mis cosas entender el fruto que los trabajos de sus estudios han hecho. Todas mis desgracias, desconsuelos y enojos, me parece que se me han ya pasado y desaparecido como humo o espuma que con el aire [f. 413v] o frío se deshace. Deme licencia para irme que ya no veo la hora de comenzar mi nueva vida y de dar cuenta muy larga a mi mujer de lo aquí hemos platicado y cuánto provecho me han hecho los caminos que se la ha venido. Plega a Dios que se aprovechen de ella otro tanto las idas y venidas que hace a su hermana la monja que no sé cuántos días ha que cada fiesta se me va a parlar con ella.

Fraile: Yo espero en Dios que lo que ella habrá oído con lo que él le dirá le hará harto provecho. Porque su hermana no le puede decir sino cosas que le inciten a vivir en amor y caridad a gloria y servicio de Dios y a contento de su marido y con buen ejemplo a su familia puesto mismo es lo que yo aquí le he dicho y dije que le diga.

CASADO: Sí dice por cierto y con mucho amor y voluntad. Mas de una cosa quiero que me dé aviso y es en qué lección me podré entretener cuando me cansaren los negocios fuera de [f. 414r] la torre de David. 
FraILE: Hay tantos y tan buenos libros que podrá escoger [...]. Mas porque para los que comienzan es inconveniente el derramarse por muchos libros para su aprovechamiento tome uno que sea de buen [ilegible] y devoto y vaya gustando de él poco a poco que hace muy al caso que lo que se lee se entienda y guste. Y no piense que se saca más provecho de leer más libros sino que el que escogiere, como le va leyendo, vaya poniendo en práctica los consejos que para su estado de vida le parece que hacen al caso y de esta suerte hallará en el libro alivio de su trabajo y remedio a su pena. Y en esa de devoción sepa que las obras de Fray Luis de Granada tienen grande doctrina. Y también este librillo que debajo de este título de La Torre de David ahora se ha imprimido tiene algunas cosillas buenas que parece que hacen el propósito y se dejan entender por ser cosas que los hombres tratamos con las manos cada día. Porque trata cómo [f. 414v] el casado se ha de haber con su mujer, como ha de criar sus hijos, cómo ha de gobernar su casa, esa es lo que de él toca. Aunque también trata de otros estados y así digo que es doctrina apacible aunque no muy subida y así se deja entender.

CASADO: Cierto que al presente lo que más hace a mí propósito es eso. Yo me voy con su licencia y no iré a casa sin él si lo hallo en casa del librero y con tanto quede Dios en su compañía.

El diálogo cuarto (ff. 414v-438v), finalmente, retoma la historia entre las dos hermanas, la casada y la monja «las cuales aplazadas para este día se juntan para comunicar y tratar el medio y remedio que la casada debía tener para vivir en paz y amor con su marido conforme a lo que en la vez pasada habían tratado. Da noticia la casada del provecho que de la plática pasada resulta y la monja el contento que tiene del buen suceso». De nuevo, se recomienda la lectura de la primera parte de La Torre de David:

MonJA: Hay tantos libros de romance que enseñan estas cosas que por su culpa de quien sabe leer las ignora. Ya os dije que andaba por ahí un librillo que se intitula Torre de David que enseña maravillosamente cómo se han de amar los casados para vivir con mucha paz y contento. Y a los clérigos lo mismo. Y a los frailes otro tanto. Y pues sabéis leer, aprovechaos del que así os hago yo.

CASADA: Podrá ser que le compre y que me ocupe algún rato en esa lectura (f. 427r).

Jerónimo de Lemos, como quedó dicho, jamás llegó a ver impresa su Torre de David. Las menciones a las que he aludido, por tanto, obligan a considerar que, con visos de veracidad, el monje jerónimo no fuera el autor de la Historia acaecida y que, acaso, no se trate siquiera de una reformulación de materiales heredados, como sí parece ser el caso de la Segunda parte. Pero más allá de quien fuera el autor de una $\mathrm{u}$ otra parte, el trabajo filológico emprendido permite afirmar que el conjunto de textos conforman - como si de una unidad se tratara - una suerte de manual de costumbres cuya función no es otra que la pedagogía de una forma 
de vida cristiana para un tiempo convulso. Todos ellos van dirigidos, «a todo género de gentes», tal y como nos decía el propio Jerónimo de Lemos en el epígrafe de la primera parte y matizaba después en el prólogo:

Aquí hallará el grande y el pequeño, el rico y el pobre, el flaco y el grueso, el sano y el enfermo, y finalmente todos hallarán todas las armas conforme a su persona, y necesidad. Por eso se llama Torre de David, que está edificada con sus almenas, de la cual cuelgan mil escudos, y todas las armas de los fuertes, que son las autoridades de la sagrada escritura, y los consejos y sentencias de los santos, con que cada uno se puede armar para se defender, o resistir a su contrario (Prólogo).

Se trata, en suma, de un corpus que importa situar en un momento histórico de tránsito a la Modernidad que viene acompañado de agudas transformaciones. En ese contexto, que es el de la Europa inquieta de las reformas, cobra necesariamente una importancia capital la literatura en torno al tema del matrimonio, forma esencial de organización del cuerpo social ligada, a su vez, a temas tan candentes como el celibato y la vida más o menos ejemplar del clero. El diálogo, a lo largo del siglo, se alza por ello como forma privilegiada de llevar a cabo la tarea didáctica relativa al matrimonio y la moral sexual, cuestiones sujetas ellas mismas a interpretaciones varias hasta bien entrados los tiempos del concilio ${ }^{13}$.

13 Tal y como afirma Pérez García, al que sigo, hubo de ser esencial el ejemplo de Erasmo y sus Coloquios, que empiezan a imprimirse en 1518 aunque es, sobre todo, desde 1522 y en las sucesivas ediciones latinas ampliadas con nuevos coloquios aparecidas entre 1523 y 1526 , cuando se conviertan en un verdadero manual dialogado de la vida cristiana que sintetizaba su pensamiento. Entre ellos ocuparía un lugar central el Uxor mempsigamos (1523). En España, las principales obras en lengua castellana dedicadas al matrimonio también adoptarían la forma dialogada: así el Norte de los estados de fray Francisco de Osuna (Sevilla, 1531) o los Coloquios matrimoniales de un Pedro de Luján (Sevilla, 1550). Pérez García sitúa al Norte de los estados al final de la coyuntura de floración de diálogos en castellano que se abre en 1525 con el nuevo ambiente humanista de la época de Carlos V y la influencia de Erasmo; ello tiene que ver con su carácter de respuesta a las ideas del holandés. La relación de la forma dialogada con el tema del matrimonio va más allá, pues otros diálogos de carácter misceláneo también dedicaron un espacio específico al matrimonio, como los Diálogos de Filosofia natural y moral (Granada, 1558) de Pedro de Mercado (en el diálogo séptimo dedicado a los estados), o los Diálogos de varias cuestiones (Alcalá, 1577) de Lorenzo Suárez de Chaves (en concreto los diálogos VIII al XIV) (2016: 232). 


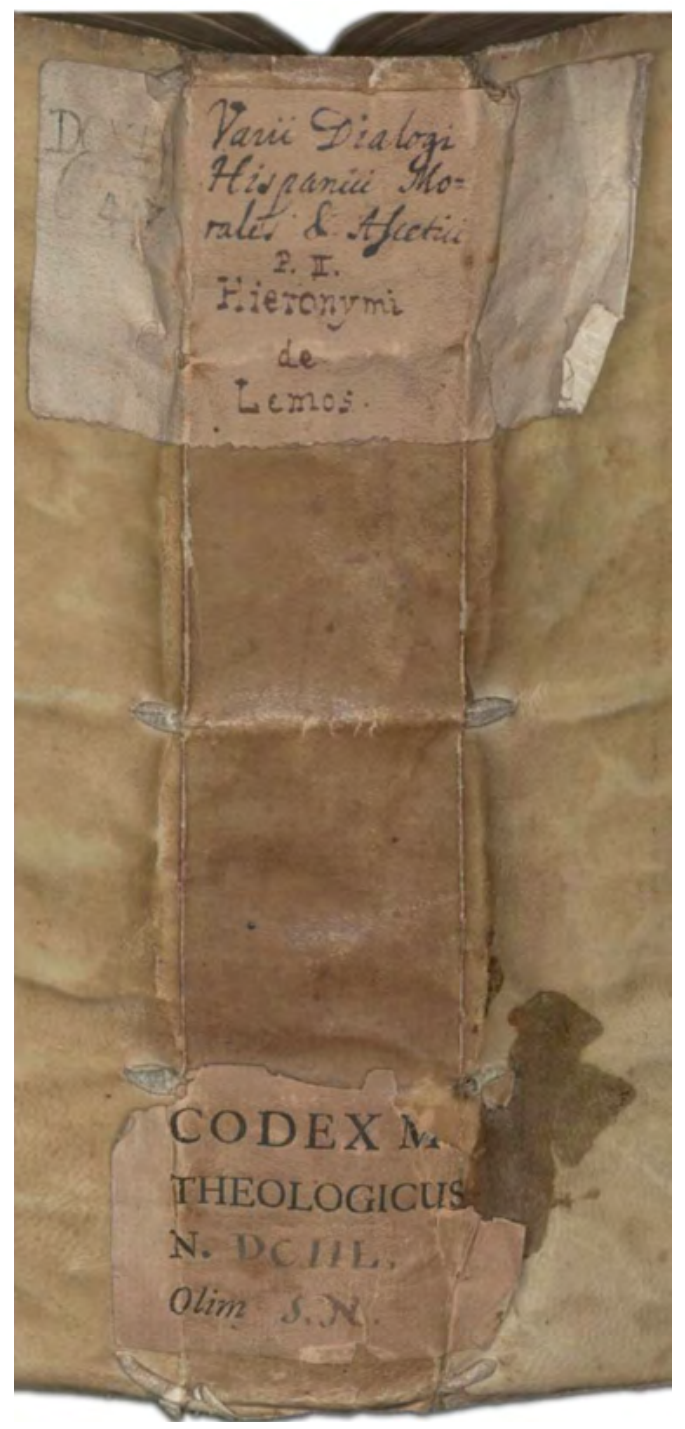

Österreichische Nationalbibliothek, Codex Vindobonensis Palatinus 11657 [Sign. Cod. 11657 Han]. 


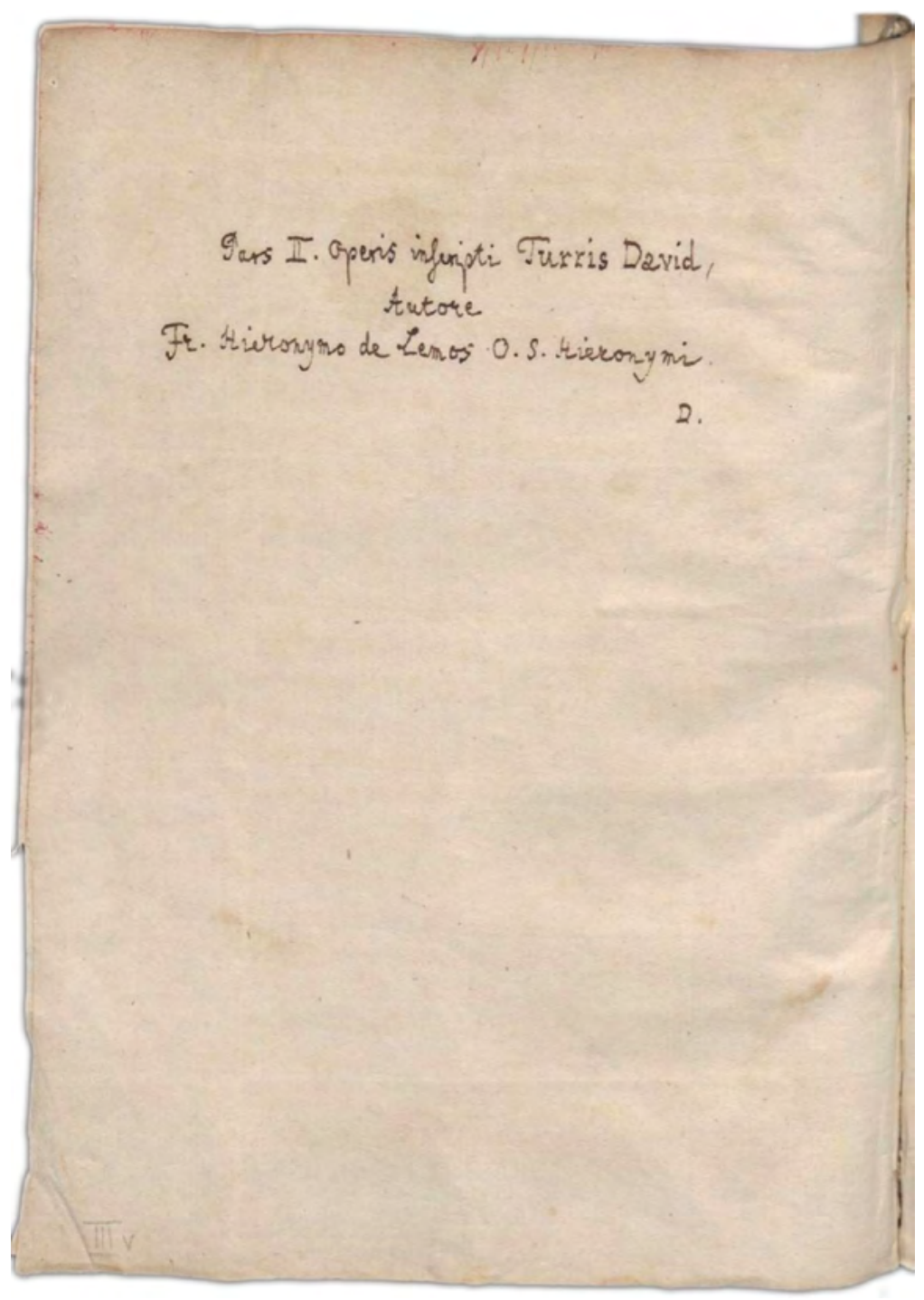

Österreichische Nationalbibliothek, Codex Vindobonensis Palatinus 11657

[Sign. Cod. 11657 Han]. 


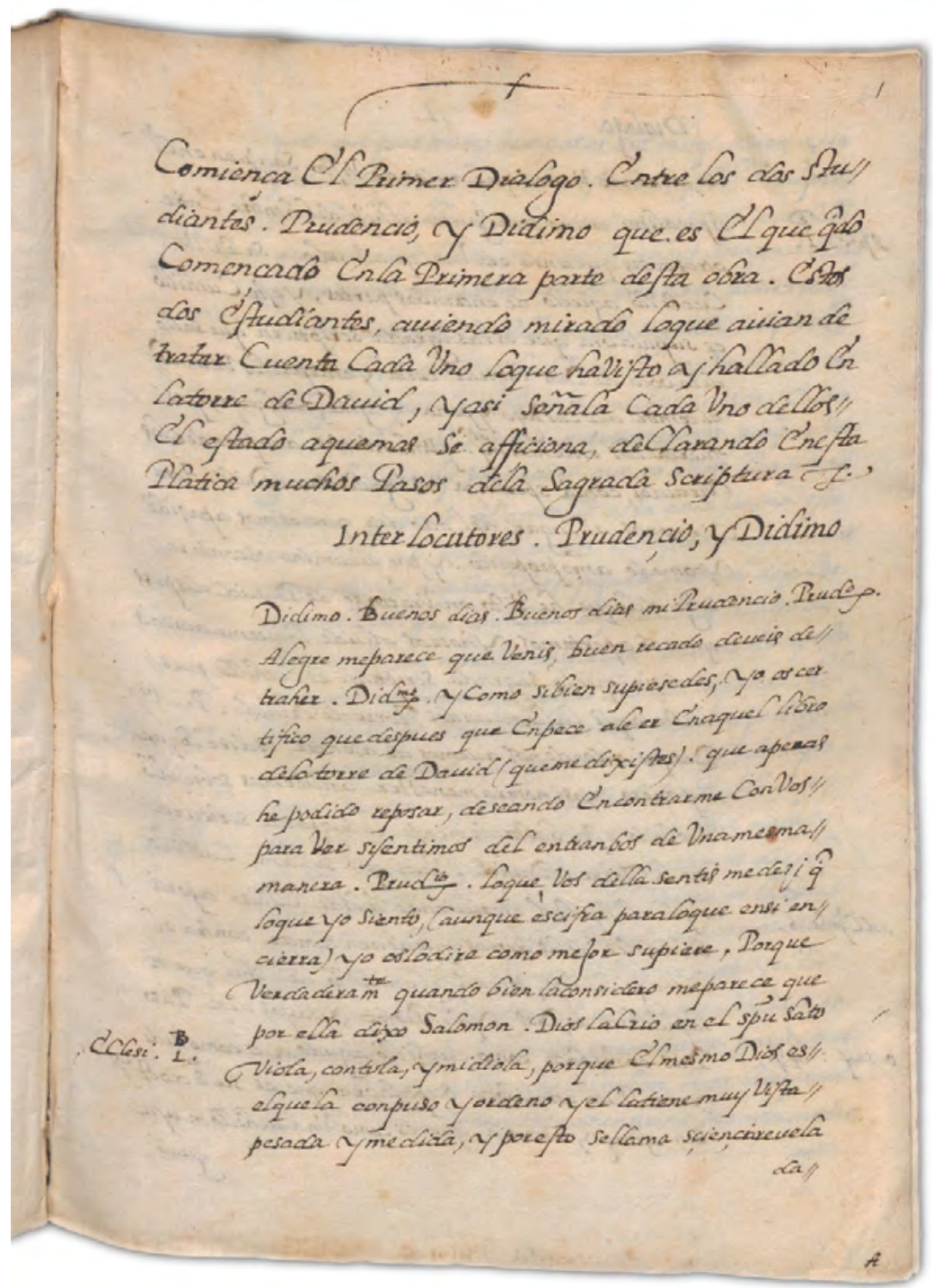

[Segunda parte de la Torre de David], ff. 1r-348v

Österreichische Nationalbibliothek, Codex Vindobonensis Palatinus 11657 [Sign. Cod. 11657 Han]. 


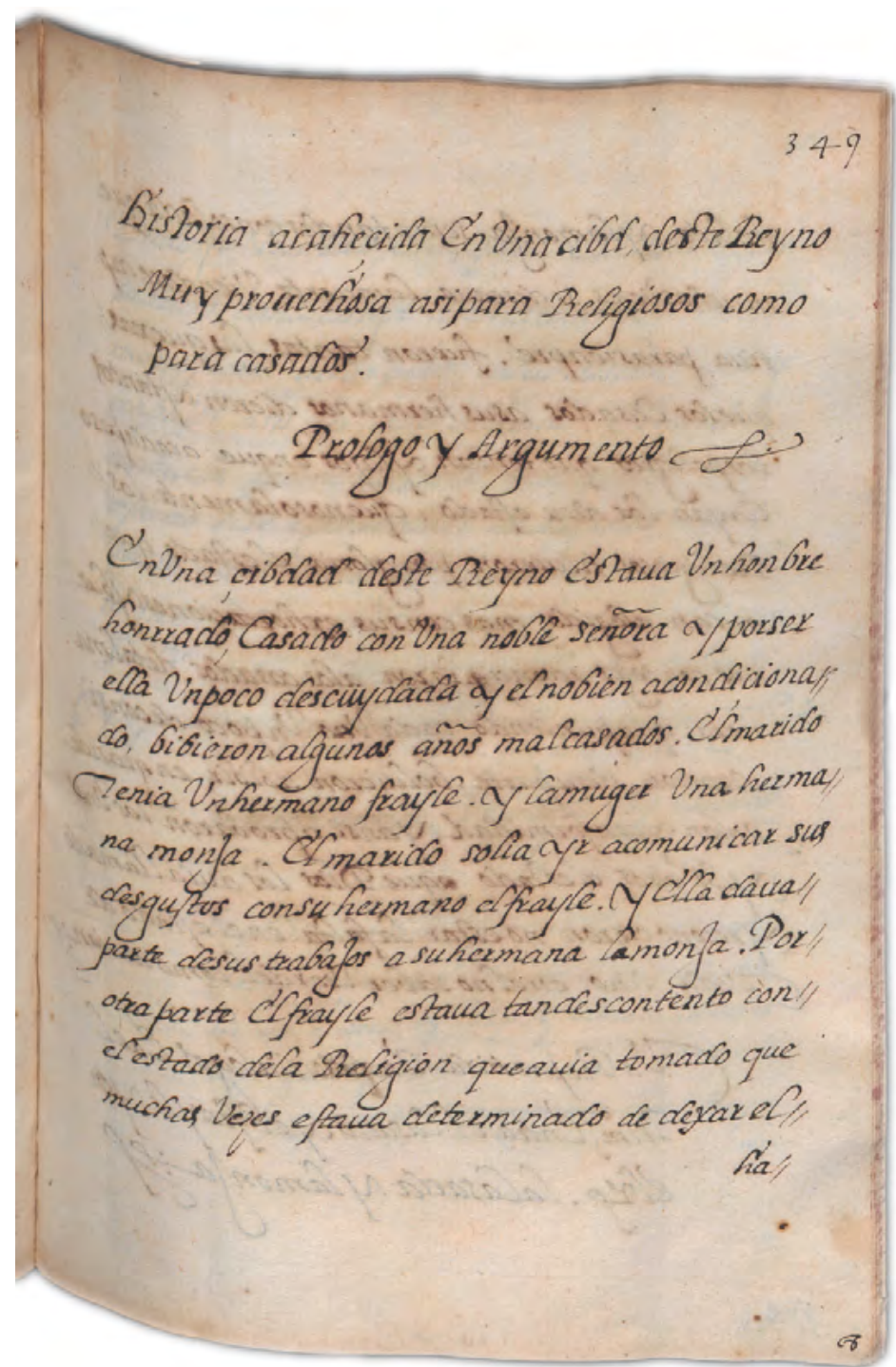

Historia acahecida en una cibdad deste reino muy provechosa asi para religiosos como para casados, ff. 349r-438v. Österreichische Nationalbibliothek, Codex Vindobonensis Palatinus 11657 [Sign. Cod. 11657 Han]. 


\section{BIBLIOGRAFÍA}

Abad, Camilo María (1954). El venerable P. Luis de la Puente, de la Compañia de Jesús: sus libros y su doctrina espiritual. Comillas: Universidad Pontificia.

Antonio, Nicolás (1783). Bibliotheca Hispana nova sive Hispanorum scriptorum qui ab anno MD ad MDCLXXXIV floruere notitia, tomus primus. Madrid: Joaqchinum de Ibarra.

Baeza y GonzÁlez, Tomás (1877). Apuntes biográficos de escritores segovianos... [Segovia]: Sociedad Económica Segoviana de Amigos del País, pp. 92-93.

Brandenberger, Tobias (1996). Literatura de matrimonio (Península Ibérica, s. XIV-XVI). Lausanne, Zaragoza: Sociedad Suiza de Estudios Hispânicos y Pórtico Editores.

CAAmaño Tomás, Alejandro (2007). «El diálogo y la literatura de matrimonio en la España del siglo XVI». Fuentes Humanisticas, 19, 35, pp. 145-156.

Colmenares, Diego de (1640). Vida y escritos de escritores segovianos que dedica a la posteridad y buen ejemplo Diego de Colmenares su compatriota. En Historia de la insigne ciudad de Segovia. Segovia: [s.e.], pp. 732-733.

Denis, Michael (1794). Codices Manuscripti Bibliothecae Palatinae Vindobonensis Latini Aliarumque Occidentis Linguarum. Viena: J.-T. de Trattnern, vol. I, pars II.

Espejo Surós, Javier (2018). «La Segunda parte de La Torre de David moralizada por vía de diálogos de Jerónimo de Lemos. Notas sobre su hallazgo y bosquejo de análisis de sus estrategias argumentativas». e-Spania, $29<$ http://journals. openedition.org/e-spania/27378> [Consulta: 02/09/2018]; DOI http://dx.doi.org/ 10.4000/e-spania.27378.

Hernández Ruiz de Villa, Rafael (1958). El libro del monasterio de Santa María del Parral de Segovia. Segovia: Instituto Diego de Colmenares.

MARINO, Giuseppe (2013). La literatura devocional española en Italia: estudio de sus traducciones [tesis doctoral]. Madrid: Universidad Autónoma de Madrid $<\mathrm{https}$ :// repositorio.uam.es/handle/10486/660385> [Consulta: 20/08/2018].

Pérez García, Rafael M. (2016). «Francisco de Osuna frente a Erasmo. El norte de los estados y la controversia dialogada acerca del matrimonio». En Ana Vian Herrero, $\mathrm{M}^{\mathrm{a}}$ José Vega Ramos y Roger Friedlein (eds.), Diálogo y censura en el siglo XVI (España y Portugal). Madrid / Frankfurt a. M.: Iberoamericana / Vervuert, pp. 229-250.

Pérez Pastor, Cristóbal (1887). La imprenta en Toledo. Descripción bibliográfica de las obras impresas en la imperial ciudad desde 1483 hasta nuestros días. Madrid: Imp. de Manuel Tello.

RodríGuez, Isaías (1932-1995). «Lemos (Jérome de), hiéronymite, $†$ 1563». En Dictionnaire de spiritualité ascétique et mystique. Doctrine et histoire. Paris: Beauchesne, vol. 9 , col. 588 .

Ruiz Fidalgo, Lorenzo (1994). La Imprenta en Salamanca. 1501-1600. Madrid: Arco Libros. 
SÁInz Rodríguez, Pedro (1984). Antología de la literatura espiritual española: siglo XVI. Madrid: Fundación Universitaria Española, t. II, pp. 210-227.

SigüEnZA, fray José de (1600). Segunda parte de la Historia de la Orden de San Geronimo: dirigida al Rey Nuestro Señor, don Philippe III por fray Ioseph de Siguença, de la misma Orden. Madrid: Imprenta Real / Iuan Flamenco [Madrid: NBAE, VIII, 1907, p. 550].

Tabulae codicum manu scriptorum, praeter graecos et orientales in Bibliotheca Palatina Vindobonensi asservatorum. Edidit Academia Caesarea Vindobonensis. Códices 11501-14000. Viena: Gerold, 1875, vol. VII, p. 26.

Vergara y Martín, Gabriel María (1904). Ensayo de una colección bibliográfico-biográfica de noticias referentes a la provincia de Segovia. Guadalajara: Taller tipográfico del Colegio de Huérfanos de la Guerra.

Recibido: 25/09/2018

Aceptado: 22/10/2018 


\section{(2)}

Nuevos apuntes a Propósito de la SEGUNDA PARTE DE LA TORRE DE DAVID MORALIZADA POR VÍA DE DIÁlogos (¿DE JeRÓNIMO de Lemos?) Y dE UNA HISTORIA ACAECIDA EN UNA CIUDAD DE ESTE REINO MUY PROVECHOSA ASI PARA RELIGIOSOS COMO PARA CASADOS

RESUMEN: Estas líneas proponen una interpretación de los materiales literarios alojados en el Codex Vindobonensis Palatinus 11657 (Österreichische Nationalbibliothek, Sign. Cod. 11657 Han.), la Segunda parte de la Torre de David moralizada por vía de diálogos para todo género de gente, perdida durante siglos, y una desconocida Historia acaecida en una ciudad de este reino muy provechosa asi para religiosos como para casados. El trabajo filológico permite considerar que, con visos de veracidad, Jerónimo de Lemos no pudo ser autor de la Historia acaecida y que, acaso, no se trate siquiera de una reformulación de materiales heredados, como sí parece ser el caso de la Segunda parte. Más allá de quién fuera el autor de una $u$ otra parte, el conjunto de textos gozan una unidad que los convierte en una suerte de manual de costumbres cuya función no es otra que la pedagogía del matrimonio y de una forma de vida cristiana para un tiempo convulso.

PALABRAS ClAVEs: Jerónimo de Lemos, matrimonio, diálogos hispánicos.

NeW insight into the Segunda parte de La Torre de David moralizada por vía dE DIÁLOGOS (FROM JERÓNIMO DE LEMOS?) AND A CERTAIN HISTORIA ACAECIDA EN UNA CIUDAD DE ESTE REINO MUY PROVECHOSA ASÍ PARA RELIGIOSOS COMO PARA CASADOS

ABSTRACT: These lines propose an interpretation of two literary works found in the Codex Vindobonensis Palatinus 11657 (Österreichische Nationalbibliothek, Sign. Cod. 11657 Han.): the Segunda parte de la Torre de David moralizada por vía de diálogos para todo género de gente, lost during centuries; and an unknown Historia acaecida en una ciudad de este reino muy provechosa así para religiosos como para casados. Philological considerations delivered here allow us to suggest that Jerónimo de Lemos could not be the author of the Historia acaecida. Indeed, it is very probable that the latter not be the outcome of rewriting of previous materials, as it seems, on the contrary, to be the case for the Segunda parte. Independently from considerations on their authorship, the set of texts studied here represents a certain unity conferring them the role of manual of customs with an underlying function of promoting the pedagogy of marriage and a Christian way of life in a convulsed time.

KEYWORDS: Jerónimo de Lemos, marriage, Hispanic literary dialogues. 


\section{Edad de Oro. Revista de Filología Hispánica}

ISSN: 0212-0429 - ISSNe: 2605-3314 <https://revistas.uam.es/edadoro/index>

Edad de Oro es uno de los máximos referentes en el área de investigación en Filología Hispánica, especialmente de los siglos XVI y XVII. Goza de un amplio reconocimiento en el ámbito académico internacional. Desde 1982 publica ininterrumpidamente, con una periodicidad anual, colaboraciones científicas de los principales especialistas de diversos centros nacionales y extranjeros. Con un público compuesto esencialmente por investigadores y expertos de todo el mundo, se dirige a cualquier persona interesada en las nuevas corrientes de los estudios humanísticos de su campo.

Dirección:

María Jesús Zamora Calvo

(Univ. Autónoma de Madrid)

Subdirección:

José Antonio Llera Ruiz

(Univ. Autónoma de Madrid)

Secretaría:

Raquel Arias Careaga

(Univ. Autónoma de Madrid)

Consejo de redacción:

Cecilia López-Ridaura

(ENES. Morelia / Univ. Nacional

Autónoma de México)

José Luis Ocasar Ariza

(Univ. Autónoma de Madrid)

Rocío Pérez Gironda

(Univ. Autónoma de Madrid)

Carolina Fernández Cordero

(Iberoamericana-Vervuert)

Admisión de originales:

María Jesús Zamora Calvo

Edad de Oro

Universidad Autónoma de Madrid

Facultad de Filosofía y Letras

Departamento de Filología Española

Campus Cantoblanco

28049 Madrid (España)

Tfno. (+34) 914976886

Correo-e: mariajesus.zamora@uam.es

Distribución, suscripción y venta:

Servicio de Publicaciones de la UAM

Universidad Autónoma de Madrid

28049 Madrid (España)
Intercambio de publicaciones:

Biblioteca de Humanidades

Universidad Autónoma de Madrid

28049 Madrid (España)

Comité científico:

Carlos Alvar (Université de Gèneve)

Ignacio Arellano (Univ. de Navarra)

Alberto Blecua

(Univ. Autónoma de Barcelona)

Jean Canavaggio

(Université Paris Nanterre)

Aurora Egido (Univ. de Zaragoza)

Víctor García de la Concha (RAE)

Luciano García Lorenzo (CSIC)

Joaquín González Cuenca

(Univ. de Castilla la Mancha)

Agustín de la Granja López

(Univ. de Granada)

Begoña López Bueno (Univ. de Sevilla)

Michel Moner

(Universitè Toulouse - Jean Jaurès)

Joan Oleza (Univ. de Valencia)

Alfonso Rey

(Univ. de Santiago de Compostela)

Lina Rodríguez Cacho

(Univ. de Salamanca)

Leonardo Romero Tobar

(Univ. de Zaragoza)

Aldo Ruffinatto

(Università degli Studi di Torino)

Lía Schwartz

(City University of New York)

Han colaborado en este volumen:

Departamento de Filología Española

(UAM)

Facultad de Filosofía y Letras (UAM)

Edad de Oro se recoge en las siguientes bases de datos y directorios: DICE; HLAS; MLA International Bibliography; PIO; ISOC-CSIC; DIALNET; SUMARIS CBUC; ULRICH'S.

Se encuentra evaluada en: SCOPUS: Q2; SCImago: SJR 2017 0.11, H Index 4; ERIH Plus: category A; CIRC: categoría C; RESH: 0.162; MIAR: ICDS 2017 10.0; CARHUS Plus+: C; LATINDEX. 


\section{EDAD DE ORO}

Revista de Filología Hispánica XXXVII

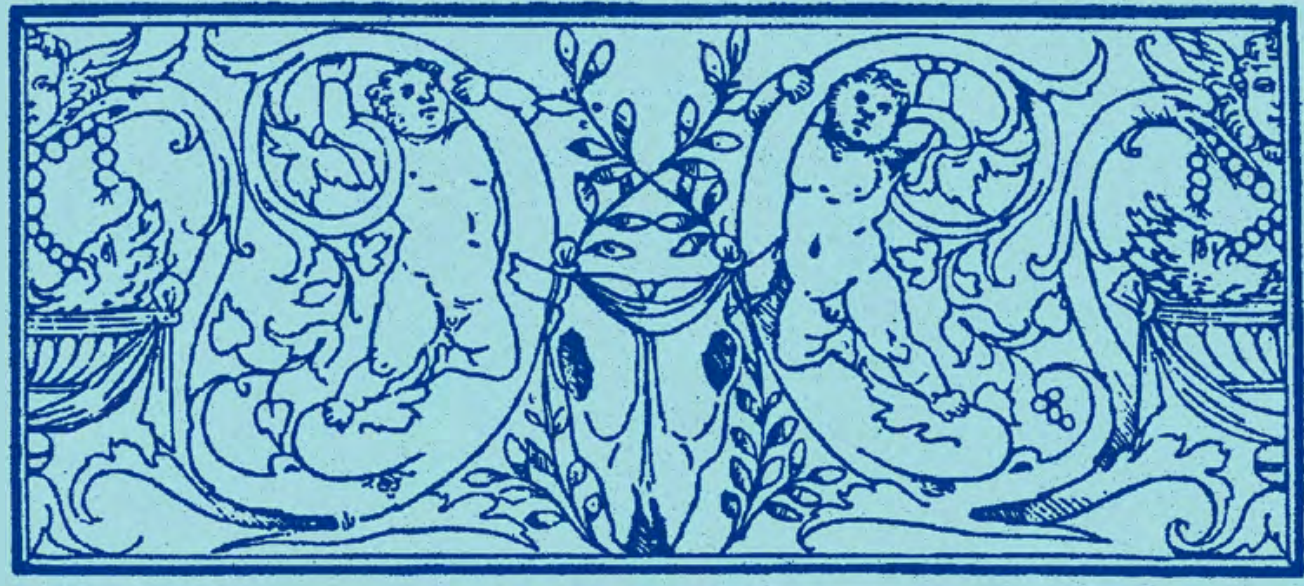

\section{DEPARTAMENTO DE FILOLOGÍA ESPAÑOLA}

EDICIONES DE LA UNIVERSIDAD AUTÓNOMA DE MADRID 